\title{
Vigor de sementes de brócolos submetidas a coberturas biodegradáveis e micronutrientes ${ }^{1}$
}

\author{
Juliana A. Batista ${ }^{2}$; Patrícia S. Tanada-Palmu ${ }^{2}$; Francisco A. Passos ${ }^{3}$; Paulo E. Trani ${ }^{3}$; Carlos R.F. Grosso ${ }^{2}$ \\ ${ }^{2}$ UNICAMP-FEA, Depto. Alimentos e Nutrição, C. Postal 6121, 13083-862 Campinas-SP; E-mail: grosso@fea.unicamp.br; ${ }^{3}$ IAC- \\ APTA,Centro de Horticultura, C. Postal 28, 13001-970, Campinas-SP; E-mail: fapassos@iac.sp.gov.br
}

\section{RESUMO}

O desenvolvimento e a aplicação de filmes ou coberturas biodegradáveis na horticultura são técnicas praticadas há vários anos, que visam promover melhoria na qualidade do produto. no presente trabalho desenvolveu-se e caracterizou-se biofilmes de pectina, gelatina e ácidos graxos e verificou-se sua eficiência como cobertura para sementes de brócolos (Brassica oleracea L. var. italica). Os filmes foram caracterizados quanto à solubilidade em água. A contagem e a observação de plantas de brócolos, a partir da germinação de sementes cobertas e não cobertas foi realizada em média a cada três dias, aos 27 dias fêz-se a quantificação da matéria fresca e seca. Os filmes de pectina e ácido esteárico foram $100 \%$ solúveis em água, enquanto os elaborados com pectina e gelatina (1/1) foram apenas $18 \%$. A aplicação das coberturas filmogênicas nas sementes de brócolos não afetou a emergência das plantas, demonstrando assim sua potencialidade para uso comercial. Os fertilizantes molibdato de sódio $\left(0,2 \mathrm{mg} \mathrm{L}^{-1}\right)$ e ácido bórico $\left(1 \mathrm{mg} \mathrm{L}^{-1}\right)$, aplicados juntamente com os biofilmes, também não afetaram a emergência e o desenvolvimento das plantas.

Palavras-chave: Brassica oleracea L. var. italica, recobrimento, biofilme, pectina, gelatina.

\begin{abstract}
Vigor of broccoli seeds submitted to biodegradable coatings and micronutrients

The development and application of biodegradable coatings and films have been used for many years in order to improve quality of the coated or packed product. The development and characterization of pectin and pectin/gelatin-based biofilms with fatty acids was evaluated and verified their efficiency as coatings to broccoli seeds (Brassica oleracea L. var. italica). The solubility in water of the films was determined. The counting and visual observations of the germinated broccoli seeds were done each three days and fresh and dried weight of the plants were determined at the end of the experiment. Pectin-based films with stearic acid were $100 \%$ soluble in water and composite films of pectin and gelatin were $18 \%$. The application of the biodegradable coatings on broccoli seeds had no effect on the plants development, showing their potential for commercial use. The fertilizers, sodium molibdate $\left(0.2 \mathrm{mg} \mathrm{L}^{-1}\right)$ and boric acid ( $\left.1 \mathrm{mg} \mathrm{L}^{-1}\right)$, added to the coating solution had no interference in the emergence and development of the broccoli plants.
\end{abstract}

Keywords: Brassica oleracea L. var. italica, coating, biofilm, pectin, gelatin.

(Recebido para publicação em 25 de maio de 2004 e aceito em 20 de maio de 2005)

$\mathrm{B}^{\mathrm{i}}$ iofilmes são materiais elaborados a partir de hidrocolóides e/ou substâncias hidrofóbicas e têm por objetivo controlar a migração de água de um sistema alimentício, a permeabilidade ao oxigênio e ao dióxido de carbono, a migração lipídica, além de manter qualidades desejáveis em um alimento relacionadas à cor, ao sabor, ao aroma, à doçura, à acidez e à textura. Podem ainda, conter aditivos alimentícios como antioxidantes e antimicrobianos (MCHUGH; KROCHTA, 1994; KESTER; FENNEMA, 1986).

Os biofilmes, quando aplicados em sementes, consistem na deposição de uma fina e uniforme camada sobre a superfície das mesmas (DUAN; BURRIS, 1997), e podem fornecer proteção contra danos mecânicos no ma- nuseio e à penetração de microrganismos e insetos. Também podem regular a entrada de água e oxigênio necessários à germinação das sementes (MENEZES, 2003). Em casos de aplicação de pesticidas em sementes, o uso da cobertura faz-se importante, pois pode reduzir o contato da pele humana com o produto químico e também diminuir o risco de contaminação do meio ambiente, incluindo o lençol freático e a destruição de insetos benéficos à lavoura (TAYLOR et al., 2001; BAUDET; PERES, 2004). A adição de agroquímicos ou nutrientes em soluções filmogênicas destinadas à cobertura de sementes tem sido estudada, buscando observar a sobrevivência das plantas germinadas (MARK et al., 1985) e também com o propósito de reduzir a apli- cação desses produtos após a emergência das plantas (ESTER et al., 1997a; ESTER et al., 1997b). O processo de recobrimento de sementes envolve um acúmulo gradual de sucessivas camadas do material de cobertura nas sementes (SCOTT, 1989).

Uma cobertura com aspecto contínuo e sem rupturas ao ser aplicada sobre sementes, pode agir como barreira protetora reduzindo os prejuízos físicos ocorridos durante o manuseio e os procedimentos de semeadura (WEST et al., 1985). Em sementes de soja, foi observada a influência do recobrimento em situação de alta concentração de vapor de água, com o objetivo de manter a qualidade da semente. A proteção durante a estocagem foi confirmada para a semente recoberta com cloreto de

\footnotetext{
${ }^{1}$ Parte integrante da dissertação de mestrado do primeiro autor, realizada na Faculdade de Engenharia de Alimentos da UNICAMP.
} 
polivinilideno. Após 24 horas de exposição sob condições de saturação, a umidade dessa semente aumentou apenas $9 \%$, enquanto que nas sementes nãorecobertas o aumento da umidade foi de 17\% (WEST et al., 1985).

A utilização de ceras para o recobrimento de sementes, em múltiplas camadas, origina sementes resistentes à absorção de água, atrasando assim a emergência das plântulas. No entanto, os polímeros altamente higroscópicos não afetam esse caráter (ALMEIDA, 2002). A secagem da cobertura aplicada nas sementes também é um parâmetro importante a ser considerado para evitar aglomerações das mesmas (TAYLOR et al., 2001).

A busca por novas alternativas para a agricultura, trazendo benefícios ao homem, tem sido alvo de inúmeros investimentos no campo da pesquisa científica. No entanto, detalhes específicos das metodologias utilizadas para o recobrimento de sementes geralmente são segredos comerciais (BAUDET; PERES, 2004). A aplicação de coberturas que proporcionem a garantia de maior taxa de germinação pode contribuir positivamente no âmbito do agronegócio, em especial em sementes de alto valor genético e cultural, submetidas a tratamentos com agroquímicos modernos de amplo espectro (REICHENBACH, 2004).

O objetivo deste trabalho foi desenvolver biofilmes à base de pectina, gelatina e ácido esteárico, caracterizá-los quanto à solubilidade em água e aplicálos como cobertura, adicionada ou não de micronutrientes, em sementes de brócolos para avaliar sua eficiência na germinação e no vigor das sementes.

\section{MATERIAL E MÉTODOS}

Foram utilizados para condução deste experimento: pectina de baixo teor de esterificação (30\%), amidada (18\%), não padronizada e obtida a partir de frutas cítricas foi cedida pela CPKelco Brasil S/A; gelatina tipo A cedida pela Leiner Davis (caracterizada pelo produtor como: bloom 240 e granulometria 6 mesh); triacetina cedida pela Rhodia; ácido esteárico (Vetec); sementes de brócolos, cultivar Ramoso, totalmente isentas de agrotóxicos, molibdato de sódio PA (Labor) e ácido bórico (Borax Holdings), como fonte de micronutrientes, cedidos pelo Instituto Agronômico de Campinas (IAC). O trabalho experimental foi realizado na Unicamp; o recobrimento das sementes efetuado no ITAL e os ensaios de germinação no IAC.

O processo de elaboração dos filmes de pectina adicionados de triacetina e ácido esteárico é descrito a seguir: uma solução de pectina (PEC) $2 \%(\mathrm{p} / \mathrm{v}$ ) foi mantida sob aquecimento a $60^{\circ} \mathrm{C}$, com agitação magnética moderada até completa solubilização. Um teor de $1 \%$ (p/ p) do plastificante triacetina (TRI), em relação ao peso da PEC, foi adicionado à solução, mantendo-se o aquecimento e a agitação magnética durante cinco minutos. Em seguida, um teor de $6 \%$ (p/ p) de ácido esteárico, também em relação ao peso de PEC, foi solubilizado em placa aquecedora a $80^{\circ} \mathrm{C}$ e transferido à solução de PEC contendo TRI. Essa solução filmogênica, em $\mathrm{pH}$ natural, foi mantida sob aquecimento a $60^{\circ} \mathrm{C}$ e agitação forte até completa incorporação do lipídio na solução de PEC. Alíquotas de $38 \mathrm{ml}$ foram pipetadas, distribuídas em placas plaxiglass de $14 \mathrm{~cm}$ de diâmetro e mantidas a temperatura ambiente $\left(25^{\circ} \mathrm{C}\right)$, em superfícies niveladas, durante 33 horas para secagem. Posteriormente, foram retirados das placas e armazenados em dessecadores, a $25^{\circ} \mathrm{C}$ e $52 \% \pm 2 \%$ de umidade relativa (UR), durante 48 horas antes da análise de solubilidade.

A elaboração dos filmes compostos de pectina e gelatina foi realizada da seguinte maneira: inicialmente uma solução de $10 \mathrm{~g}$ de gelatina (GEL) em 100 $\mathrm{ml}$ de água foi deixada em repouso à temperatura ambiente $\left(25^{\circ} \mathrm{C}\right)$, durante uma hora para hidratar. Em seguida, a solução foi aquecida em banho-maria a $90^{\circ} \mathrm{C}$, durante 10 minutos. Paralelamente, uma solução de PEC 2\% (p/v) foi mantida em aquecimento e agitação até que todo o material se solubilizasse, como descrito anteriormente. Após o preparo, $50 \mathrm{ml}$ da solução de PEC foram misturados com $50 \mathrm{ml}$ da solução de GEL. A essa mistura, foi adicionado $1 \%$ (p/p) de TRI, em relação ao peso total de matéria seca da solução que foi mantida durante três minutos sob agita- ção magnética moderada e aquecimento de $60^{\circ} \mathrm{C}$. Alíquotas de $28 \mathrm{ml}$ foram pipetadas e distribuídas em placas plaxiglass de $14 \mathrm{~cm}$ de diâmetro. Após 30 horas de secagem à temperatura ambiente e sobre superfície nivelada, os filmes foram retirados das placas e armazenados em dessecadores, a $25^{\circ} \mathrm{C}$ e $52 \% \pm 2 \%$ UR, durante 48 horas antes do início das análises.

A análise de solubilidade (SOL) em água dos filmes foi realizada em triplicata, seguindo o método proposto por Gontard et al. (1994). Inicialmente, os filmes foram cortados em discos de $2 \mathrm{~cm}$ de diâmetro, secos em estufa com circulação de ar (Tecnal, TE394/2) a $105^{\circ} \mathrm{C}$ por 24 horas, pesados e então imersos em $50 \mathrm{ml}$ de água destilada, mantidos sob agitação lenta e periódica por 24 horas à temperatura ambiente $\left(25^{\circ} \mathrm{C}\right)$, em banho-maria (Tecnal, TE057). Os fragmentos de filme restante foram retirados do banho e secos em estufa $\left(105^{\circ} \mathrm{C}, 24\right.$ horas) para determinação da massa seca final dos mesmos.

As sementes foram recobertas com as soluções filmogênicas PEC/AE e PEC/GEL elaboradas conforme procedimento descrito acima produzindo os tratamentos $\mathrm{T}_{1}$ (PEC/AE) e $\mathrm{T}_{2}$ (PEC/ GEL). Adicionalmente os fertilizantes molibdato de sódio (Mo) $\left(0,2 \mathrm{mg} \mathrm{L}^{-1}\right)$ e ácido bórico (B) $\left(1 \mathrm{mg} \mathrm{L}^{-1}\right)$ foram adicionados nas duas soluções filmogênicas para constituição de outros dois tratamentos $\left(\mathrm{T}_{3}=\mathrm{PEC} / \mathrm{AE}+\mathrm{Mo}+\right.$ $\mathrm{B}$ e $\left.\mathrm{T}_{4}=\mathrm{PEC} / \mathrm{GEL}+\mathrm{Mo}+\mathrm{B}\right)$. Dessa forma, cinco tratamentos foram utilizados para este experimento, sendo um deles o controle $\left(\mathrm{T}_{5}=\right.$ sementes sem cobertura e sem adição de Mo e B ao solo).

Para o recobrimento da semente com as soluções, foi utilizada uma drageadeira (INCAL, modelo JAA110E, capacidade 5 L) ("pan coating"), no Instituto de Tecnologia de Alimentos (ITAL) de Campinas, com velocidade de $25 \mathrm{rpm}$ e jato de ar frio. Cerca de $10 \mathrm{~g}$ de semente foram colocadas nesse aparelho e, em seguida, $1 \mathrm{~g}$ da solução filmogênica foi adicionado às sementes, aguardando-se quatro minutos para nova adição da solução, até que um total de cinco camadas fosse obtido.

Os testes de vigor da semente foram realizados em casa de vegetação, do Centro de Horticultura do IAC, com 
delineamento estatístico inteiramente casualizado e quatro repetições. Cada parcela experimental correspondeu a um vaso de alumínio, de $18 \mathrm{~cm}$ de diâmetro por 15 $\mathrm{cm}$ de altura. Cerca de quatro dias antes da semeadura, os vasos foram lavados com solução de Super Cândida® (hipoclorito de sódio, hidróxido de sódio, cloreto de sódio e água) contendo de 2 a 2,5\% de cloro ativo (p/p). Foram diluídos $150 \mathrm{ml}$ do produto em 10 litros de água. No dia anterior à semeadura, os vasos foram preenchidos com solo peneirado (peneira de $4 \mathrm{~mm}$ de malha) proveniente de local não cultivado, que a seguir, foi tratado através de uma rega com solução de Mancozeb, eficaz para o controle de fungos patogênicos, eventualmente presentes em solos agricultáveis (20 $\mathrm{g}$ do produto por 10 litros de água).

Sementes com tamanhos semelhantes foram selecionadas e distribuídas em número de 18 , por parcela, em tres fileiras (seis sementes por fileira). Após a colocação das sementes, $55 \pm 5 \mathrm{ml}$ de solo foram adicionados sobre as mesmas.

Os vasos foram distribuídos aleatoriamente em bandejas plásticas e a umidade do solo foi mantida próxima à saturação. A contagem do número de plântulas emergidas em cada tratamento foi realizada nos $3^{\circ} ; 7^{\circ} ; 10^{\circ} ; 13^{\circ} ; 16^{\circ}$; $20^{\circ} ; 23^{\circ}$ e $27^{\circ}$ dias após a semeadura .Após esse período, as plantas emergidas foram cortadas no colo e pesadas em balança semi-analítica para a determinação da massa da matéria fresca de cada parcela. Posteriormente, as plantas foram mantidas 24 horas em estufa com circulação de ar (Tecnal, TE394/2) a $65^{\circ} \mathrm{C}$, para determinação da massa da matéria seca.

A análise estatística dos dados foi efetuada por meio de análises de variância (ANOVA) e do teste de Tukey, utilizado para determinar as diferenças significativas das médias das propriedades dos filmes e das médias das determinações realizadas nas plantas de brócolos, com intervalo de $95 \%$ de confiança. O programa computacional Statistica ${ }^{\circledR} 5.5$ (Stasoft, USA) foi utilizado para esses cálculos.

\section{RESULTADOS E DISCUSSÃO}

Os filmes apresentaram facilidade quanto ao manuseio e mostraram-se vi-

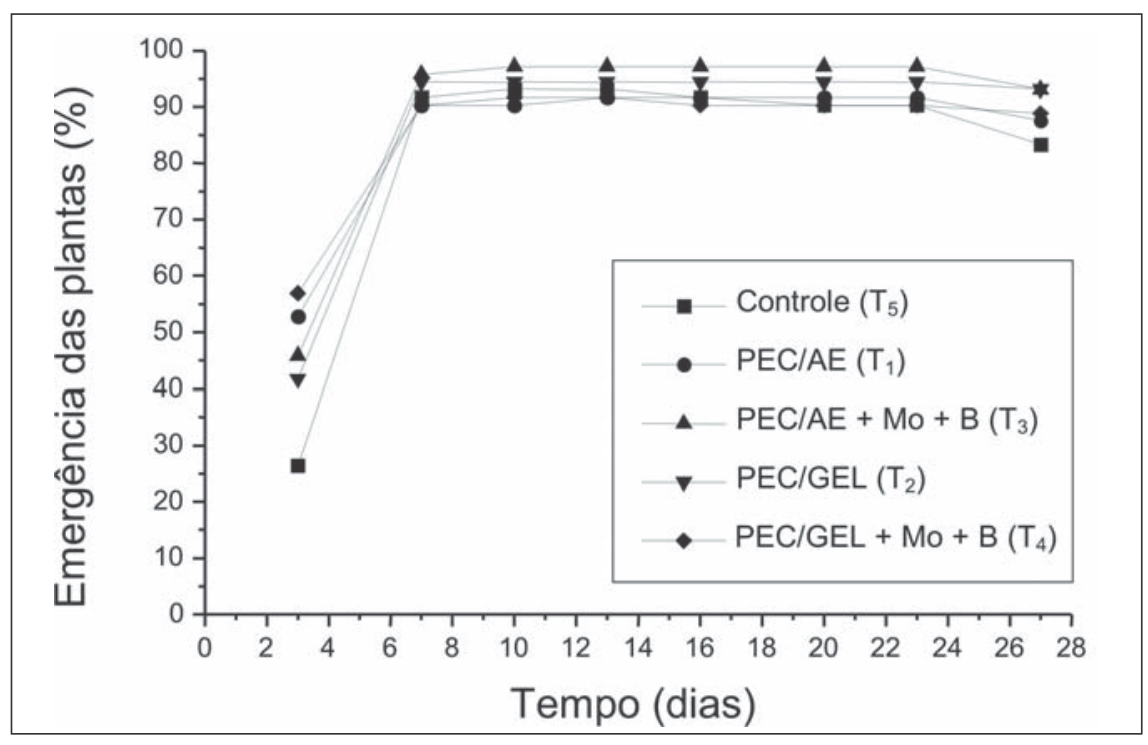

Figura 1. Emergência das plântulas mantidas em casa de vegetação durante vinte e sete dias. Campinas, UNICAMP, 2003.

sualmente homogêneos. Em relação à solubilidade, os mesmos apresentaram valores contrastantes, sendo o filme de PEC/AE $100 \%$ solúvel, mesmo com a presença do ácido esteárico na composição, enquanto o de PEC/GEL foi aproximadamente $18 \%$.

Segundo Shih (1996), normalmente os polissacarídeos são altamente higroscópicos e se desintegram rapidamente em água. Em semente o uso de coberturas hidrofílicas tem apresentado oportunidades de promover rápida e completa germinação das mesmas (SCOTT, 1989).

A mistura de PEC/GEL (1/1) apresentou menor solubilidade, em relação ao filme de PEC/AE, provavelmente devido à presença da gelatina. Fakhouri et al. (2003), ao caracterizarem filmes de gelatina (10\%) adicionados de $5 \%$ de triacetina, encontraram solubilidade em torno de $14 \%$.

A cobertura, ao ser aplicada, promove aumento no peso da semente e uniformiza o tamanho e o formato das mesmas (SCOTT, 1989). Esse aumento de peso, apesar de pequeno, também foi verificado no presente trabalho, após o procedimento de aplicação das coberturas, onde todos os tratamentos apresentaram ganho em torno de $2 \%$ em relação ao peso inicial.

Em relação à emergência, no $3^{\circ}$ dia, o tratamento controle apresentou em torno de $26 \%$ de plântulas emergidas, enquanto os demais variaram de $41 \%$ a $57 \%$ (Figura 1). A maior capacidade de emergência, na fase inicial, encontrada nos tratamentos com aplicação de coberturas, pode ter sido decorrente da hidrofilicidade do material utilizado, apesar dos valores contrastantes obtidos para a solubilidade.

A partir do $7^{\circ}$ dia de semeadura, todos os tratamentos apresentaram valores relacionados ao vigor das sementes, em torno de $90 \%$. Esses foram ligeiramente reduzidos a partir do $23^{\circ}$ dia, acentuando-se no $27^{\circ}$ dia, quando foram observadas algumas plantas mortas (Figura 1), provavelmente devido ao efeito de competição dentro da parcela e/ou incidência de fungos de solo.

West et al. (1985) verificaram que a aplicação da cobertura à base de cloreto de polivinilideno (PVDC), em semente de soja, promoveu germinação mais rápida do que sem a cobertura. Em condições limitadas de umidade, como freqüentemente ocorre no campo, a cobertura de semente pode agir como um coletor de água por capilaridade ou aumentar a tensão superficial e beneficiar a capacidade de germinação. Entre os exemplos de aplicação de coberturas poliméricas em semente, podem ser citados o algodão e a soja, que apresentaram aumentos de $20 \%$ a $30 \%$ no índice de germinação (MARK et al., 1985). 
Tabela 1. Caracterização dos teores de matérias fresca e seca e contagem do número de plântulas emergidas após vinte e sete dias da semeadura das sementes de brócolos tratadas com aplicação de coberturas, na presença ou ausência dos micronutrientes boro e molibdênio. Campinas, UNICAMP, 2003.

\begin{tabular}{lccc}
\hline $\begin{array}{l}\text { Tratamento da } \\
\text { semente }\end{array}$ & $\begin{array}{c}\mathbf{N}^{\circ} \text { de } \\
\text { plantas/parcela }\end{array}$ & $\begin{array}{c}\text { Matéria } \\
\text { fresca/parcela }(\mathbf{g})\end{array}$ & $\begin{array}{c}\text { Matéria } \\
\text { seca/parcela }(\mathbf{g})\end{array}$ \\
\hline Controle & $15,00 \pm 2,71 a$ & $11,61 \pm 1,49 a$ & $1,61 \pm 0,24 a$ \\
PEC/AE & $15,75 \pm 2,36 a$ & $10,24 \pm 1,68 a$ & $1,35 \pm 0,25 a$ \\
PEC/AE+ Mo+B & $16,75 \pm 0,50 a$ & $10,77 \pm 0,78 a$ & $1,53 \pm 0,11 a$ \\
PEC/GEL & $16,75 \pm 2,06 a$ & $11,55 \pm 0,67 a$ & $1,50 \pm 0,09 a$ \\
PEC/GEL+ Mo+B & $16,00 \pm 1,41 a$ & $10,71 \pm 1,53 a$ & $1,48 \pm 0,33 a$ \\
\hline
\end{tabular}

${ }^{a}$ Médias e desvio padrão das médias na mesma coluna com letras sobrescritas iguais não diferem significativamente ao nível de $\mathrm{P}<0,05$, de acordo o teste de Tukey.
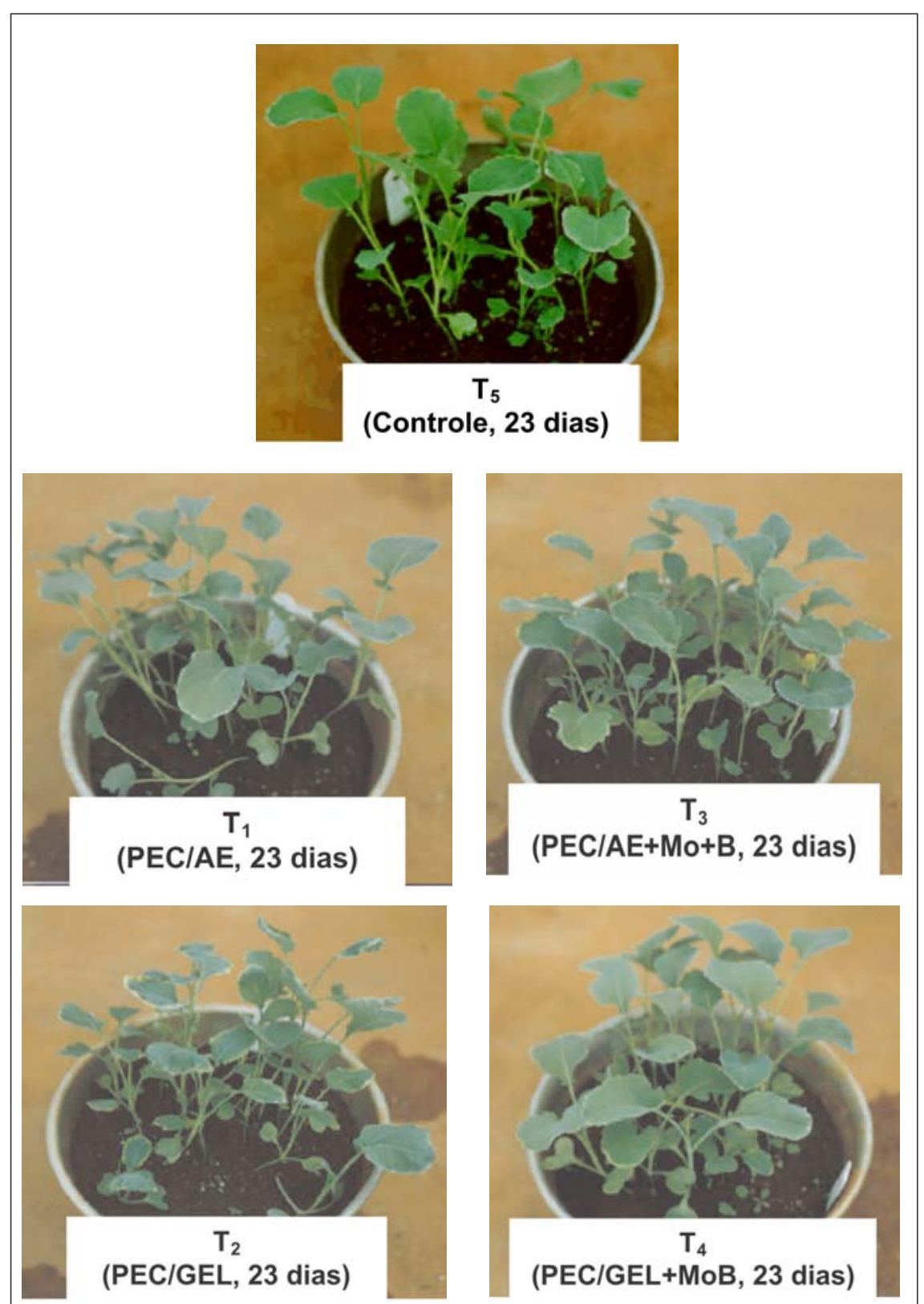

Figura 2: Aspecto visual das plântulas emergidas no 23ำ dia após a semeadura de sementes de brócolos. Campinas, UNICAMP, 2003.
Decorridos vinte e sete dias da semeadura, foi realizada a contagem de plantas emergidas. Não foi detectada diferença estatística entre os tratamentos (Tabela 1), indicando que o tratamento aplicado na semente não interferiu na emergência das plântulas.

As análises realizadas quanto aos teores de matéria seca e fresca das plantas de brócolos também não mostraram diferenças significativas entre os tratamentos. A massa da matéria seca é um modo mais preciso para comparação do que a massa da matéria fresca, a qual pode ter influência da perda de água para o ambiente.

Os nutrientes boro e molibdênio, adicionados à solução de cobertura da semente, são necessários para o crescimento das plantas e de difícil distribuição uniforme em campos de cultivo, na forma de fertilizantes aplicado ao solo, devido à quantidade necessária ser muito reduzida. Essa aplicação de nutrientes adicionados em soluções filmogênicas pode funcionar como uma alternativa para uma distribuição uniforme dos micronutrientes próximos à semente, de fácil incorporação e de baixo custo de implementação. A quantidade dos micronutrientes boro e molibdênio adicionados às formulações de PEC/AE e PEC/GEL não promoveu interferência na emergência e no desenvolvimento das plantas ao final do experimento, conforme pode ser observado na Figura 2, onde podem ser observados tamanho, número e aparência das plantas, semelhantes entre todos os tratamentos. Isso, provavelmente, deveu-se ao fato desses micronutrientes estarem presentes no solo em quantidades suficientes para suprir a necessidade das plantas no período considerado. Como as coberturas não se mostraram tóxicas, podem ser recomendadas no caso de deficiência temporária ou não de boro e molibdênio.

Foram realizados estudos para traçar a influência de alguns fertilizantes, como sulfato de zinco e borax, adicionados aos "pellets", na qualidade inicial da semente, na emergência e no potencial em campo e no armazenamento (por mais de três meses) de semente de soja (SRIMATHI et al., 2002). Peletizando a semente com a adição de sulfato de zinco $\left(250 \mathrm{mg} \mathrm{kg}^{-1}\right.$ 
de semente), houve melhora na sua qualidade inicial e no potencial de produção. Esses autores também observaram que o desempenho da semente peletizada, com e sem nutrientes, foi melhor do que no controle. O poder de germinação da semente foi mantido por mais de três meses sem redução significativa na qualidade inicial.

Assim, os filmes à base de pectina e ácido esteárico foram $100 \%$ solúveis em água, enquanto os elaborados com pectina e gelatina (1/1) foram apenas $18 \%$ solúveis. A aplicação de coberturas filmogênicas na semente de brócolos, com ou sem ácido bórico (1 $\left.\mathrm{mg} \mathrm{L}^{-1}\right)$ e molibdato de sódio $(0,2 \mathrm{mg}$ $\mathrm{L}^{-1}$ ), não afetou a emergência e o crescimento das plantas (mudas), demonstrando, assim, sua potencialidade para uso comercial.

\section{AGRADECIMENTOS}

Os autores agradecem ao CNPq pela concessão da bolsa de mestrado à Juliana Alves Batista, ao Centro de Horticultura do IAC por permitir a utilização de sua infra-estrutura e também ao ITAL (Campinas) pelo uso dos equipamentos.

\section{LITERATURA CITADA}

ALMEIDA, C. Recobrimento de sementes de brócolos em leito de jorro e leito fluidizado. 2002. 148 f. (Tese Doutorado) - FEQ, UNICAMP, Campinas.

BAUDET, L.; PERES, W. Recobrimento de sementes. SEED News, n.1, p.20-23, 2004.

DUAN, X.; BURRIS, J.S. Seed physiology, production \& technology. Crop Science, v.37, n.2, p.515-520, 1997.

ESTER, A.; VOGEL, R.; BOUMA, E. Controlling Thrips tabaci (Lind.) in leek by film-coating seeds with insecticides. Crop Protection, v.16, n.7, p.673-677, 1997a.

ESTER, A; STEENE, F; DRIEGHE, S. Effects of filmcoating Brussels sprouts seeds with various insecticides on the transport into the seedlings and on the control of cabbage root fly, Delia radicum (B.). Journal of Plant Diseases and Protection, v.104, n.1, p.47-53, 1997b.

FAKHOURI, F.M.; BATISTA, J.A.; GROSSO, C Efeito de coberturas comestíveis aplicadas em goiabas in natura (Psidium Guajava L.) I. Desenvolvimento e caracterização de filmes comestíveis de gelatina, triacetina e ácidos graxos. Brazilian Journal of Food Technology, v.6, n.2, p.301-308, 2003.

GONTARD, N.; DUCHEZ, C.; CUQ, J.L.; GUILBERT, S. Edible composite films of wheat gluten and lipids: water vapor permeability and other physical properties. International Journal of Food Science and Technology, v.29, n.1, p.39-50, 1994.

KESTER, J.J.; FENNEMA, O.R. Edible films and coatings: a review. Food Technology, v.40, n.12, p.47-59, 1986.
MARK, H.F.; BIKALES, N.M.; OVERBERGER, C.G. Encyclopedia of Polymer Science and Engineering. Wiley Interscience, New York. p.611-621, 1985.

McHUGH, T.H.; KROCHTA, J.M. Milk-proteinbased edible films and coating. Food Technology, v.48, n.1, p.97-103, 1994.

MENEZES, N.L. A semente e sua germinação. Santa Maria: UFSM. Disponível em: <www.ufsm.br/sementes/textos/semeger.shtml>. Acesso em: 11 ago. 2003.

REICHENBACH, J. Film-coating para agregar qualidade e segurança. SEED News, n.1, p.24-25, 2004.

SCOTT, J.M. Seed coating and treatments and their effects on plant establishment. In: BRADY, N.C. (Ed.). Advances in Agronomy. California: Academic Press, 1989. v.42.

SHIH, F.F. Edible films from rice protein concentrate and pullulan. Cereal Chemistry, v.73, n.3, p.406-409, 1996.

SRIMATHI, P.; MALARKODI, K.; GEETHA, R.; KRISHNASAMY, V. Nutrient pelleting to augument quality seed production in soybean. Seed-Research-New-Delhi, v. 30, n.2, p.186-189, 2002.

TAYLOR, A.G.; ECKENRODE, C.J.; STRAUB, R.W. Seed coating technologies and treatments for onion: challenges and progress. HortScience, v.36, n.2, p.199-205, 2001.

WEST, S.H.; LOFTIN, S.K.; WAHL, M.; BATICH, C.D.; BEATTY, C.L. Polymers as moisture barriers to maintain seed quality. Crop Science, v.25, p.941-944, 1985. 